\title{
THE STRUCTURAL STRENGTH OF GLASS: HIDDEN DAMAGE
}

\author{
F. A. Veer ${ }^{\mathrm{a}, 1}$ and Yu. M. Rodichev ${ }^{\mathrm{b}, 2}$
}

UDC 539.3

\begin{abstract}
We discuss "hidden damage" of glass by the rolling process, which results in heterogeneous distribution of microcracks on the edge surface of glass element, which are the fracture source deteriorating glass element strength. It is shown that removal of this damage on the edges of glass elements increases the engineering strength of float glass significantly. Using the "hidden damage" approach, we provide strength determination for the weakest specimens that is statistically relevant and is based on a reliable engineering parameter.
\end{abstract}

Keywords: glass, rolling process, hidden damage, engineering parameter, microcracks.

Introduction. Glass is commonly used in engineering, when a transparent, durable, and stiff material is needed. Although glass is not usually used for load-bearing applications, in most cases glass still carries a load. In an automobile, the front and rear windows are an integral part of the structure responsible for a significant part of the total stiffness and resisting the considerable forces generated by the air pressure at high-speed driving.

However, the reliable value for the glass strength is an open issue: the tensile strength cannot easily be determined, since glass in direct tensile test will break at the grip. In certain cases, bending test results provide scattered values of the bending strength with a spread of 30 to $50 \%$ of the mean strength.

For glass fibers and cast glass the distribution can be adequately described using the Weibull statistic approach leading to a probabilistic strength for the glass used [1,2]. For the more common float glass this is more complicated. Results of bending experiments by various authors suggest that the processing and specimen size influence the results and suggest systematic data deviation from the Weibull statistic distribution [3-5].

A likely explanation for this is that the usual processing of float glass results in multiple types of defects which provides a multilinear Weibull plot $[6,7]$.

To investigate this systematically it was decided to look in more depth at the effect of processing on float glass strength. The initial step, which is described in this paper, deals with the effect of cutting and breaking quality on the strength of processed float glass.

Float glass is produced as $6 \times 3.21 \mathrm{~m}$ "jumbo" plates. These are cut into the required size and the cut edges are usually grinded and polished. The cutting is usually done by scratching the glass with a glazier's diamond or rolling it with a tungsten carbide roller producing a cut on the upper surface. This is schematically shown in Fig. 1. By bending the plate slightly, as is shown by the arrows, tension is generated at the cut resulting in an unstable crack-cut growing down on the figured straight arrow through the thickness separating the glass parts. Surface damages such as crumbled arrises and cross microcracks are forming on edges of both glass parts under the contact cutter action.

The depth values of these specific cross microcracks are larger than those of the initial surface microcracks which form the cracked surface layer on both sides of float glass. The length of transversal microcracks is typically larger than the width of the cut with the crumbled arrises as seen in Figs. 1 and 2.

${ }^{\mathrm{a}}$ Delft University of Technology, Delft, the Netherlands ( ${ }^{1}$ f.a.veer@tudelft.nl, www.glass.bk.tudelft.nl). ${ }^{b}$ Pisarenko Institute of Problems of Strength, National Academy of Sciences of Ukraine, Kiev, Ukraine ( ${ }^{2}$ rym@ipp. kiev.ua). Translated from Problemy Prochnosti, No. 3, pp. 93 - 109, May - June, 2011. Original article submitted January 15, 2010. 


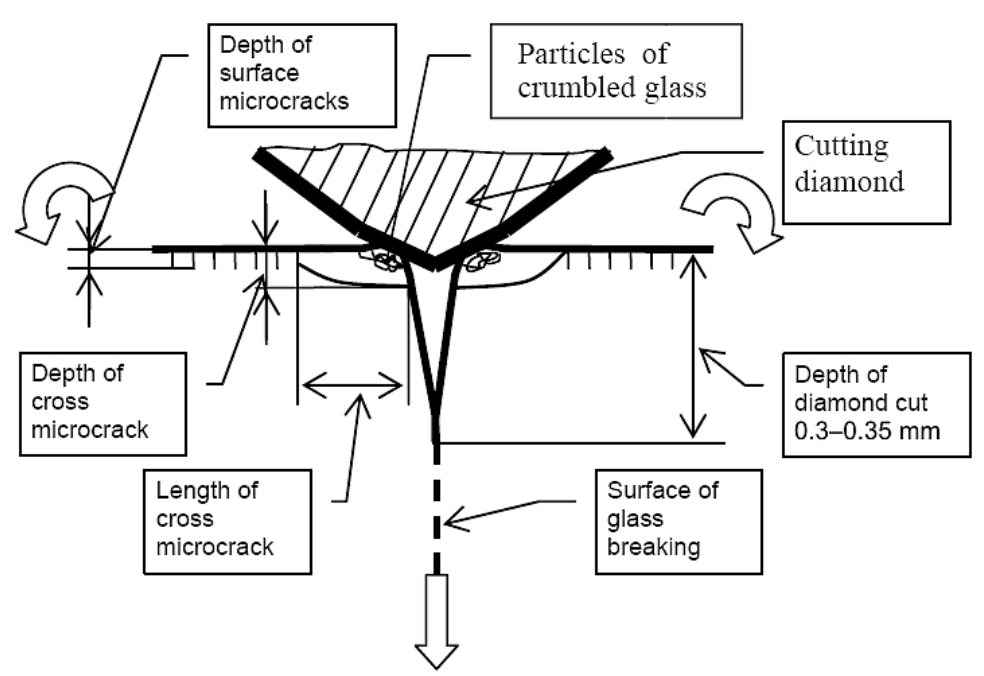

Fig. 1. Diamond cutting and cross microcracks in glass plate elements.

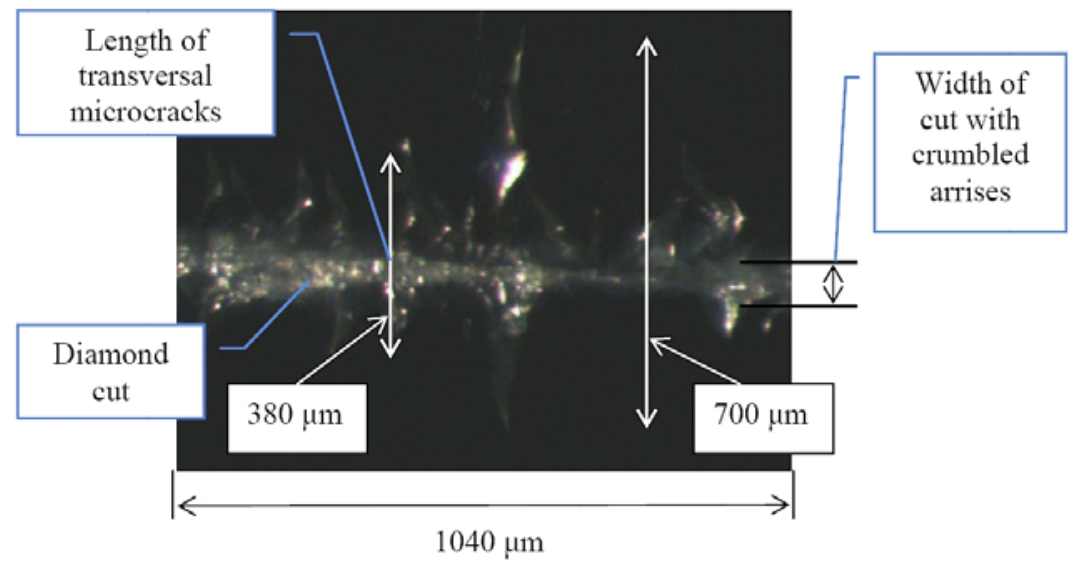

Fig. 2. Transversal microcracks in diamond cut.

Therefore these "invisible" and practically uncontrolled microcracks are root cause for the low strength of cut glass elements. Their sizes may be so large that the deepest of them may remain partially or fully after grinding and polishing of the glass element edges.

For this research 190 pieces of glass with a size of $400 \times 50 \mathrm{~mm}$ were cut from a single $6 \mathrm{~mm}$ "jumbo" panel using an automated cutting table. The length axis of the specimens corresponds to the width axis of the jumbo plate. These specimens were carefully removed, stacked and shipped.

Specimens were subjected to flat tests with the cut up (i.e., with the cut in the compression zone) and with the cut down (i.e., with the cut in the tension zone). In the standing tests, the specimens were tested with the cut left or the cut right relative to the front of the machine. The purpose of the tests was to systematically study the effect of the orientation.

The additional specimens were made more precisely and carefully protected to prevent handling damaging of the edges. These specimens were tested flat with a cut up. Their high quality broken edge arrises were in the tension zone.

Test results were compared with previous data on size effects on glass bending strength with the grinded and polished specimens up to $3.2 \mathrm{~m}$ length [8].

Methodology. All four-point bending tests were conducted using a Zwick Z100 universal testing machine under displacement control. Table 1 gives the relevant data. The rig for the standing tests was equipped with friction less antibuckling supports. All glass was wrapped in self adhesive plastic foil for safety. Before test commencement all orientations (top, bottom, left, and right) were indicated on the specimens. After testing specimens were inspected 
TABLE 1. Testing Conditions

\begin{tabular}{|c|c|c|c|c|c||}
\hline Orientation & $\begin{array}{c}\text { Height } \\
(\mathrm{mm})\end{array}$ & $\begin{array}{c}\text { Width } \\
(\mathrm{mm})\end{array}$ & $\begin{array}{c}\text { Load span } \\
(\mathrm{mm})\end{array}$ & $\begin{array}{c}\text { Support span } \\
(\mathrm{mm})\end{array}$ & $\begin{array}{c}\text { Test speed } \\
(\mathrm{mm} / \mathrm{min})\end{array}$ \\
\hline Standing test & 40 & 6 & 175 & 350 & 1 \\
\hline Flat test & 6 & 40 & 175 & 350 & 5 \\
\hline
\end{tabular}

TABLE 2. Testing Conditions for Additional Flat Test Specimens with the Cut in Compression

\begin{tabular}{||c|c|c|c|c|c|c||}
\hline $\begin{array}{c}\text { Height } \\
(\mathrm{mm})\end{array}$ & $\begin{array}{c}\text { Width } \\
(\mathrm{mm})\end{array}$ & $\begin{array}{c}\text { Load span } \\
(\mathrm{mm})\end{array}$ & $\begin{array}{c}\text { Support span } \\
(\mathrm{mm})\end{array}$ & $\begin{array}{c}\text { Average test speed } \\
(\mathrm{mm} / \mathrm{min})\end{array}$ & $\begin{array}{c}\text { Average loading speed } \\
(\mathrm{MPa} / \mathrm{s})\end{array}$ & $\begin{array}{c}\text { Number } \\
\text { of specimens }\end{array}$ \\
\hline 6 & 40 & 175 & 350 & 4.80 & 1.590 & 6 \\
\cline { 4 - 7 } & & & & 0.49 & 0.162 & 5 \\
\hline
\end{tabular}

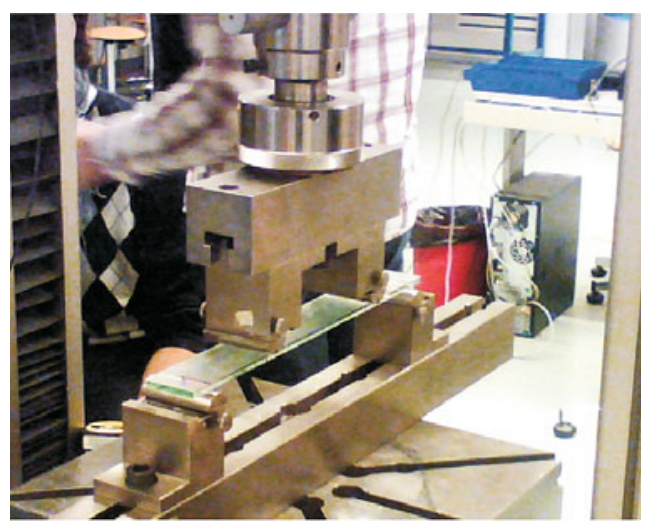

Fig. 3. Test setup for flat tests.

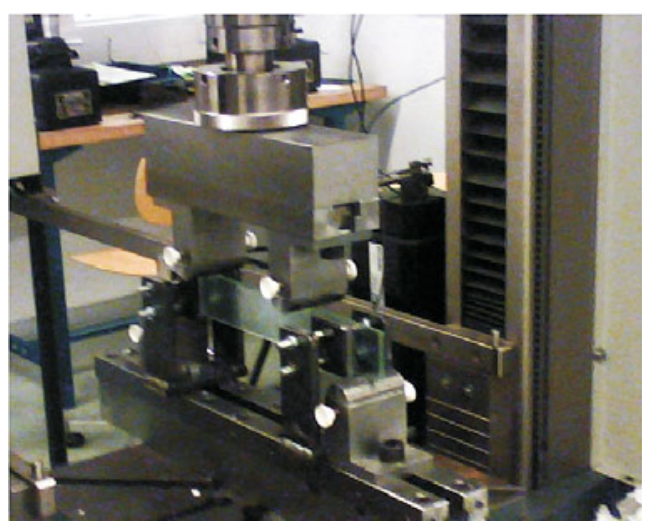

Fig. 4. Test setup for standing tests.

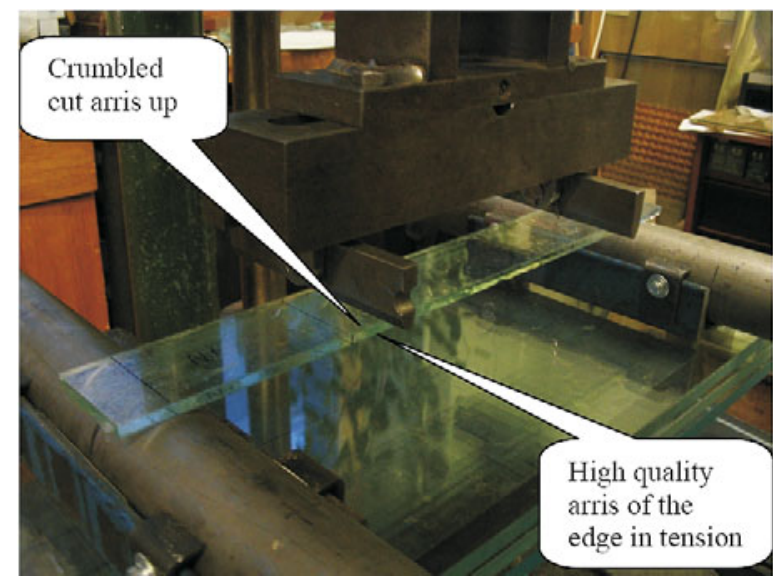

Fig. 5. Test setup for additional specimens in flat tests.

for breakage between the loading span, relative crack origin and number of cracks emanating from the failure point. The tests were conducted in a single week to ensure reasonably constant climatic conditions. During testing no changes were made to the testing machines and the supports. The tests setups are shown in Figs. 3 and 4.

Testing of additional specimens was made with flat test orientation under the same testing conditions using a ZD-4 universal hydraulic testing machine under displacement, test speed and loading speed control. Table 2 gives the relevant data. The test setup is shown in Fig. 5.

Results. The results of the flat tests are given in Table 3. Figure 6 shows a Weibull plot of the flat results with the cut in the compression zone. Figure 7 shows a Weibull plot of the flat test results with the cut in the tensile zone. 
TABLE 3. Results of Flat Tests

\begin{tabular}{|c|c|c|c|c|c|c|c|c|c|c|}
\hline No. & $\begin{array}{c}F \\
\text { cut down } \\
\text { (N) }\end{array}$ & $\begin{array}{c}\sigma_{b, \max } \\
\text { cut down } \\
(\mathrm{MPa})\end{array}$ & $\begin{array}{c}\text { Break } \\
\text { between } \\
\text { loading } \\
\text { span } \\
\text { (yes/no) }\end{array}$ & $\begin{array}{c}\text { Crack } \\
\text { from left } \\
\text { or right }\end{array}$ & $\begin{array}{l}\text { Number } \\
\text { of cracks }\end{array}$ & $\begin{array}{c}F \\
\text { cut up } \\
(\mathrm{N})\end{array}$ & $\begin{array}{l}\sigma_{b, \max } \\
\text { cut up } \\
(\mathrm{MPa})\end{array}$ & $\begin{array}{c}\text { Break } \\
\text { between } \\
\text { loading } \\
\text { span } \\
\text { (yes/no) }\end{array}$ & $\begin{array}{c}\text { Crack } \\
\text { from left } \\
\text { or right }\end{array}$ & $\begin{array}{l}\text { Number } \\
\text { of cracks }\end{array}$ \\
\hline 1 & 2 & 3 & 4 & 5 & 6 & 7 & 8 & 9 & 10 & 11 \\
\hline 1 & 357 & 52.06 & yes & left & 13 & 259 & 37.77 & yes & left & 3 \\
\hline 2 & 335 & 48.85 & yes & right & 6 & 447 & 65.19 & yes & right & 14 \\
\hline 3 & 351 & 51.19 & yes & right & 5 & 413 & 60.23 & yes & left & 17 \\
\hline 4 & 382 & 55.71 & yes & left & 9 & 373 & 54.40 & yes & right & 15 \\
\hline 5 & 405 & 59.06 & yes & right & 11 & 414 & 60.38 & yes & right & 13 \\
\hline 6 & 352 & 51.33 & yes & right & 9 & 365 & 53.23 & yes & right & 8 \\
\hline 7 & 364 & 53.08 & yes & right & 6 & 463 & 67.52 & yes & right & 12 \\
\hline 8 & 356 & 51.92 & yes & right & 5 & 467 & 68.10 & yes & left & 16 \\
\hline 9 & 386 & 56.29 & yes & left & 8 & 470 & 68.54 & yes & right & 10 \\
\hline 10 & 347 & 50.60 & yes & right & 6 & 400 & 58.33 & yes & left & 9 \\
\hline 11 & 328 & 47.83 & yes & left & 7 & 431 & 62.85 & yes & left & 14 \\
\hline 12 & 248 & 36.17 & yes & left & 1 & 360 & 52.50 & yes & left & 6 \\
\hline 13 & 340 & 49.58 & yes & right & 8 & 381 & 55.56 & yes & left & 10 \\
\hline 14 & 350 & 51.04 & yes & left & 10 & 361 & 52.65 & yes & right & 8 \\
\hline 15 & 377 & 54.98 & yes & left & 9 & 398 & 58.04 & yes & right & 8 \\
\hline 16 & 368 & 53.67 & yes & right & 13 & 375 & 54.69 & yes & right & 14 \\
\hline 17 & 382 & 55.71 & yes & right & 9 & 408 & 59.50 & yes & right & 23 \\
\hline 18 & 380 & 55.42 & yes & right & 8 & 432 & 63.00 & yes & left & 15 \\
\hline 19 & 375 & 54.69 & yes & left & 18 & 343 & 50.02 & yes & left & 5 \\
\hline 20 & 396 & 57.75 & yes & right & 7 & 301 & 43.90 & yes & left & 4 \\
\hline 21 & 340 & 49.58 & yes & right & 9 & 442 & 64.46 & yes & left & 11 \\
\hline 22 & 361 & 52.65 & yes & left & 7 & 290 & 42.29 & yes & right & 4 \\
\hline 23 & 343 & 50.02 & yes & right & 9 & 369 & 53.81 & yes & right & 10 \\
\hline 24 & 383 & 55.85 & yes & left & 17 & 467 & 68.10 & yes & right & 15 \\
\hline 25 & 366 & 53.38 & yes & right & 8 & 512 & 74.67 & yes & left & 19 \\
\hline 26 & 305 & 44.48 & yes & left & 10 & 275 & 40.10 & yes & right & 7 \\
\hline 27 & 341 & 49.73 & yes & left & 14 & 485 & 70.73 & yes & middle* & n.a. \\
\hline 28 & 397 & 57.90 & yes & middle & n.a. & 434 & 63.29 & yes & right & 16 \\
\hline 29 & 286 & 41.71 & yes & right & 11 & 554 & 80.79 & yes & left & 33 \\
\hline 30 & 384 & 56.00 & no* & right & n.a. & 683 & 99.60 & yes & right & 36 \\
\hline 31 & 303 & 44.19 & yes & left & 12 & 402 & 58.63 & yes & right & 8 \\
\hline 32 & 354 & 51.63 & yes & right & 10 & 656 & 95.67 & yes & middle* & n.a. \\
\hline 33 & 395 & 57.60 & yes & right & 3 & 302 & 44.04 & yes & right & 4 \\
\hline 34 & 238 & 34.71 & yes & right & 14 & 364 & 53.08 & yes & middle* & n.a. \\
\hline 35 & 329 & 47.98 & yes & right & 2 & 470 & 68.54 & yes & right & 17 \\
\hline 36 & 378 & 55.13 & yes & right & 14 & 349 & 50.90 & yes & right & 8 \\
\hline 37 & 337 & 49.15 & yes & right & 15 & 396 & 57.75 & yes & left & 20 \\
\hline 38 & 327 & 47.69 & yes & right & 14 & 532 & 77.58 & yes & left & 16 \\
\hline 39 & 335 & 48.85 & yes & left & 12 & 383 & 55.85 & yes & left & 9 \\
\hline 40 & 379 & 55.27 & yes & left & 15 & 539 & 78.60 & yes & right & 21 \\
\hline 41 & - & - & - & - & - & 559 & 81.52 & yes & left & 23 \\
\hline 42 & - & - & - & - & - & 418 & 60.96 & yes & left & 9 \\
\hline 43 & - & - & - & - & - & 455 & 66.35 & yes & left & 29 \\
\hline 44 & - & - & - & - & - & 257 & 37.48 & yes & right & 3 \\
\hline
\end{tabular}


Continued Table 3

\begin{tabular}{|c|c|c|c|c|c|c|c|c|c|c|}
\hline 1 & 2 & 3 & 4 & 5 & 6 & 7 & 8 & 9 & 10 & 11 \\
\hline 45 & - & - & - & - & - & 469 & 68.40 & yes & right & 17 \\
\hline 46 & - & - & - & - & - & 440 & 64.17 & yes & left & 21 \\
\hline 47 & - & - & - & - & - & 544 & 79.33 & yes & left & 29 \\
\hline 48 & - & - & - & - & - & 505 & 73.65 & yes & middle* & n.a. \\
\hline 49 & - & - & - & - & - & 517 & 75.40 & yes & left & 16 \\
\hline 50 & - & - & - & - & - & 446 & 65.04 & yes & right & 18 \\
\hline \multicolumn{2}{|c|}{ Mean } & 51.6 & left & $38 \%$ & & & 61.4 & left & $47.8 \%$ & \\
\hline \multicolumn{2}{|c|}{ std/mean } & $10.6 \%$ & & & & & $20.5 \%$ & & & \\
\hline \multicolumn{2}{|c|}{ maximum } & 59.1 & & & & & 99.6 & & & \\
\hline \multicolumn{2}{|c|}{ minimum } & 34.7 & & & & & 37.5 & & & \\
\hline
\end{tabular}

Note. Here and in Table 4: results with * are excluded from calculations and graphs.

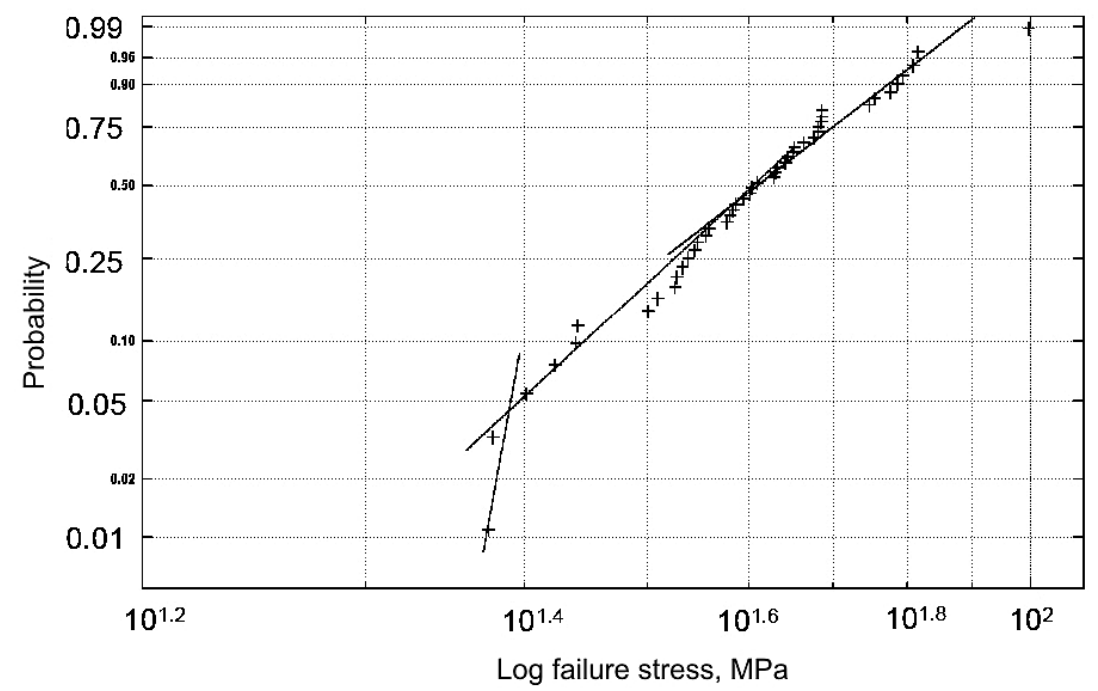

Fig. 6. Weibull plot of flat test results with the cut upwards.

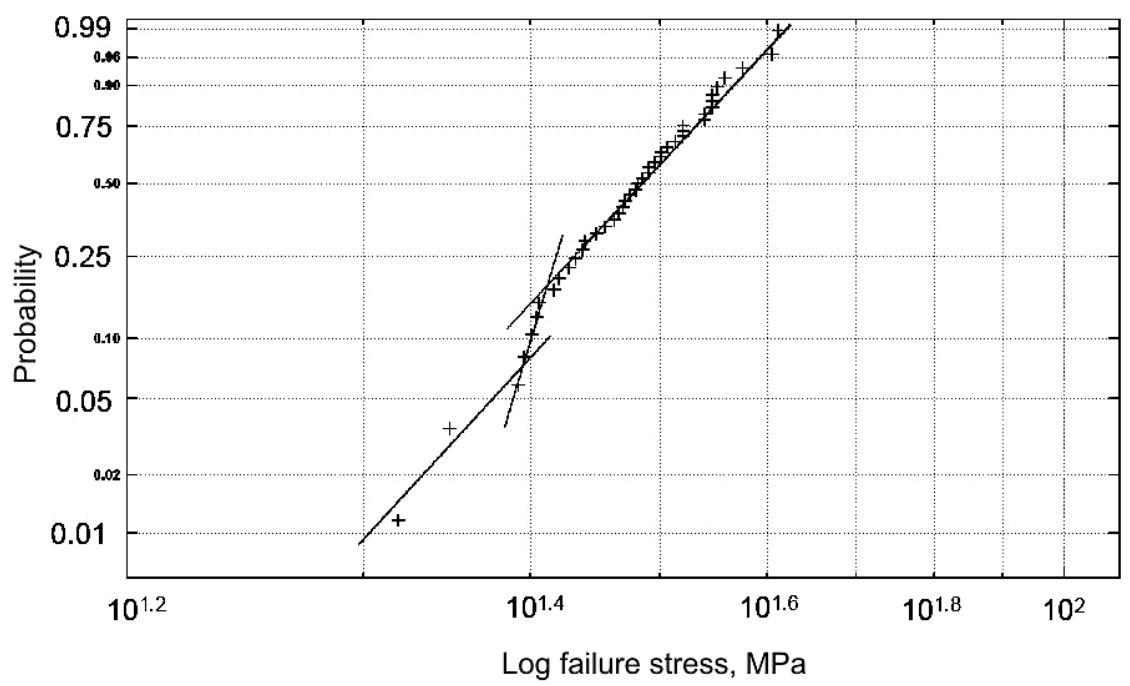

Fig. 7. Weibull plot of flat test results with the cut downwards.

The results from the standing tests are given in Table 4. Figure 8 shows a Weibull plot of the standing results with the cut left. Figure 9 shows a Weibull plot of the standing results with the cut right. 
TABLE 4. Results of Standing Tests

\begin{tabular}{|c|c|c|c|c|c|c|c|c|}
\hline No. & $\begin{array}{c}F \\
\text { cut left } \\
(\mathrm{N})\end{array}$ & $\begin{array}{c}\sigma_{b, \max } \\
\text { cut left } \\
(\mathrm{MPa})\end{array}$ & $\begin{array}{c}\text { Break } \\
\text { between } \\
\text { loading span } \\
\text { (yes/no) }\end{array}$ & $\begin{array}{l}\text { Number } \\
\text { of cracks }\end{array}$ & $\begin{array}{c}F \\
\text { cut right } \\
(\mathrm{N})\end{array}$ & $\begin{array}{c}\sigma_{b, \max } \\
\text { cut right } \\
(\mathrm{MPa})\end{array}$ & $\begin{array}{c}\text { Break } \\
\text { between } \\
\text { loading span } \\
\text { (yes/no) }\end{array}$ & $\begin{array}{l}\text { Number } \\
\text { of cracks }\end{array}$ \\
\hline 1 & 2 & 3 & 4 & 5 & 6 & 7 & 8 & 9 \\
\hline 1 & 2770 & 48.48 & yes & 5 & 3730 & 65.28 & yes & 4 \\
\hline 2 & 2800 & 49.00 & yes & 5 & 3620 & 63.35 & yes & 9 \\
\hline 3 & 2450 & 42.88 & yes & 4 & 3450 & 60.38 & yes & 7 \\
\hline 4 & 2430 & 42.53 & no* & n.a. & 3550 & 62.13 & yes & 7 \\
\hline 5 & 2860 & 50.05 & yes & 7 & 3010 & 52.68 & yes & 5 \\
\hline 6 & 2830 & 49.53 & yes & 4 & 2890 & 50.58 & yes & 7 \\
\hline 7 & 3290 & 57.58 & yes & 6 & 2780 & 48.65 & yes & 5 \\
\hline 8 & 2970 & 51.98 & yes & 5 & 2900 & 50.75 & yes & 6 \\
\hline 9 & 2860 & 50.05 & yes & 5 & 2530 & 44.28 & yes & 6 \\
\hline 10 & 2750 & 48.13 & yes & 5 & 3560 & 62.30 & yes & 9 \\
\hline 11 & 2260 & 39.55 & yes & 5 & 2740 & 47.95 & no* & n.a. \\
\hline 12 & 2740 & 47.95 & yes & 6 & 2950 & 51.63 & yes & 5 \\
\hline 13 & 1820 & 31.85 & yes & 2 & 2500 & 43.75 & no* & n.a. \\
\hline 14 & 2510 & 43.93 & yes & 4 & 3020 & 52.85 & yes & 6 \\
\hline 15 & 2560 & 44.80 & yes & 5 & 2790 & 48.83 & yes & 6 \\
\hline 16 & 2500 & 43.75 & yes & 4 & 3010 & 52.68 & yes & 5 \\
\hline 17 & 2970 & 51.98 & yes & 5 & 2730 & 47.78 & yes & 5 \\
\hline 18 & 2710 & 47.43 & yes & 4 & 2130 & 37.28 & yes & 4 \\
\hline 19 & 2240 & 39.20 & no* & n.a. & 3120 & 54.60 & yes & 7 \\
\hline 20 & 2590 & 45.33 & no* & n.a. & 3350 & 58.63 & no* & n.a. \\
\hline 21 & 1990 & 34.83 & yes & 3 & 2650 & 46.38 & no* & n.a. \\
\hline 22 & 3120 & 54.60 & yes & 6 & 3950 & 69.13 & yes & 9 \\
\hline 23 & 3190 & 55.83 & yes & 6 & 3110 & 54.43 & yes & 6 \\
\hline 24 & 2240 & 39.20 & yes & 3 & 2710 & 47.43 & yes & 6 \\
\hline 25 & 2470 & 43.23 & yes & 4 & 3050 & 53.38 & yes & 5 \\
\hline 26 & 3080 & 53.90 & yes & 7 & 3340 & 58.45 & yes & 7 \\
\hline 27 & 2440 & 42.70 & yes & 4 & 3190 & 55.83 & yes & 7 \\
\hline 28 & 2800 & 49.00 & yes & 6 & 2930 & 51.28 & no* & n.a. \\
\hline 29 & 2320 & 40.60 & yes & 5 & 2760 & 48.30 & no* & n.a. \\
\hline 30 & 2310 & 40.43 & yes & 4 & 2260 & 39.55 & yes & 4 \\
\hline 31 & 3150 & 55.13 & yes & 8 & 3420 & 59.85 & yes & 8 \\
\hline 32 & 2890 & 50.58 & yes & 5 & 3140 & 54.95 & yes & 7 \\
\hline 33 & 2930 & 51.28 & yes & 6 & 3370 & 58.98 & yes & 6 \\
\hline 34 & 2600 & 45.50 & yes & 4 & 3250 & 56.88 & yes & 7 \\
\hline 35 & 2290 & 40.08 & yes & 5 & 1870 & 32.73 & yes & 2 \\
\hline 36 & 2400 & 42.00 & yes & 4 & 3960 & 69.30 & yes & 8 \\
\hline 37 & 2660 & 46.55 & yes & 5 & 3400 & 59.50 & yes & 7 \\
\hline 38 & 3080 & 53.90 & yes & 6 & 3400 & 60.20 & yes & 9 \\
\hline 39 & 3610 & 63.18 & no* & n.a. & 3480 & 60.90 & yes & 9 \\
\hline 40 & 3460 & 60.55 & yes & 6 & 3200 & 56.00 & yes & 8 \\
\hline 41 & 2680 & 46.90 & yes & 5 & 3540 & 61.95 & yes & 9 \\
\hline 42 & 2640 & 46.20 & yes & 6 & 3270 & 57.23 & yes & 7 \\
\hline 43 & 3500 & 61.25 & yes & 9 & 3180 & 55.65 & yes & 8 \\
\hline 44 & 2120 & 37.10 & no* & n.a. & 2380 & 41.65 & yes & 6 \\
\hline 45 & 3120 & 54.60 & yes & 6 & 3090 & 54.08 & yes & 7 \\
\hline
\end{tabular}


Continued Table 4

\begin{tabular}{|c|c|c|c|c|c|c|c|c|}
\hline 1 & 2 & 3 & 4 & 5 & 6 & 7 & 8 & 9 \\
\hline 46 & 2970 & 51.98 & yes & 6 & 2810 & 49.18 & yes & 6 \\
\hline 47 & 2330 & 40.78 & no* & n.a. & 3000 & 52.50 & yes & 5 \\
\hline 48 & 2690 & 47.08 & yes & 4 & 3550 & 62.13 & yes & 10 \\
\hline 49 & 3120 & 54.60 & yes & 6 & 2910 & 50.93 & yes & 7 \\
\hline 50 & 2380 & 41.65 & yes & 3 & 2960 & 51.80 & yes & 6 \\
\hline \multicolumn{2}{|c|}{ Mean } & 47.9 & & & & 54.3 & & \\
\hline \multicolumn{2}{|c|}{ std/mean } & $13.5 \%$ & & & & $14.3 \%$ & & \\
\hline \multicolumn{2}{|c|}{ maximum } & 61.3 & & & & 69.3 & & \\
\hline \multicolumn{2}{|c|}{ minimum } & 31.9 & & & & 32.7 & & \\
\hline
\end{tabular}

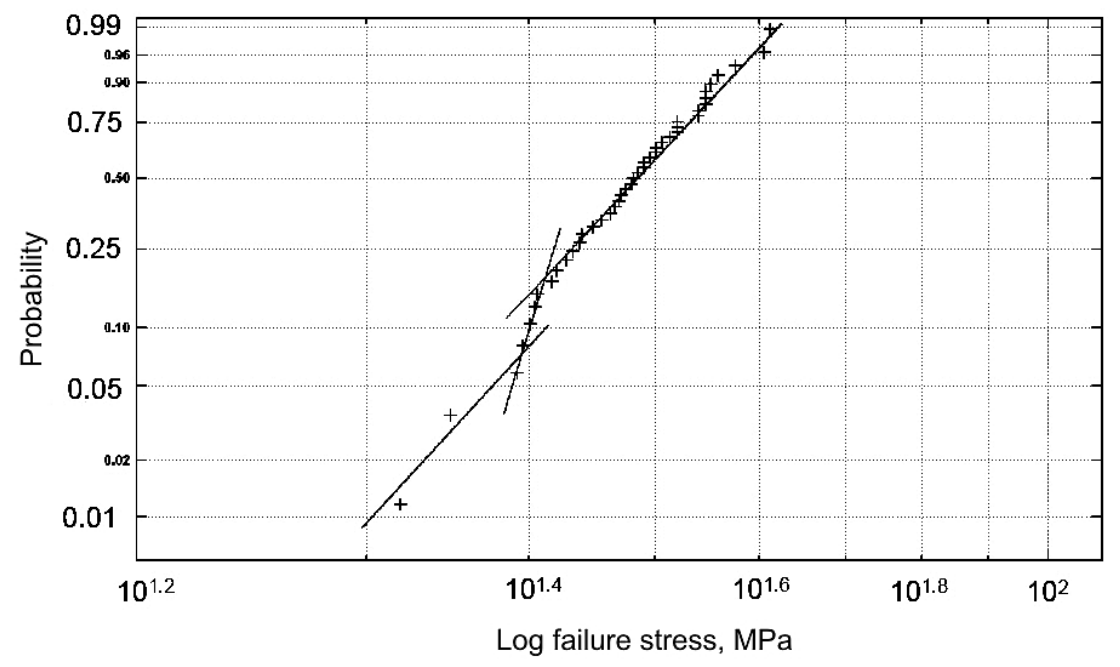

Fig. 8. Weibull plot of standing test results with the cut left.

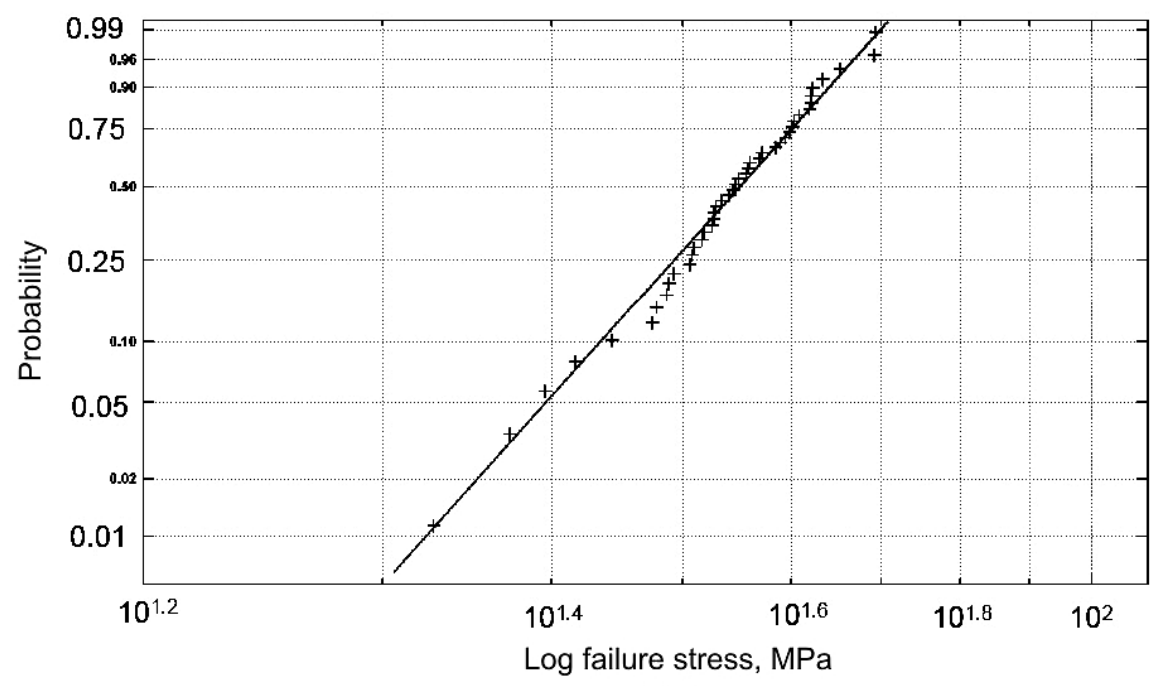

Fig. 9. Weibull plot of standing test results with the cut right.

Statistical Analysis. As there is doubt about the suitability of the Weibull distribution, the data has been analyzed using the following distributions:

(i) normal;

(ii) lognormal; 
TABLE 5. Fits to Different Statistical Functions

\begin{tabular}{||c|c|c|c|c||}
\hline Distribution & Cut up & Cut down & Cut left & Cut right \\
\hline Normal & no & no & yes & no \\
\hline Lognormal & no & no & yes & no \\
\hline Extreme value & no & yes & no & yes \\
\hline Exponential & no & no & no & no \\
\hline Rayleigh & no & no & no & no \\
\hline Weibull & no & no & yes & yes \\
\hline
\end{tabular}

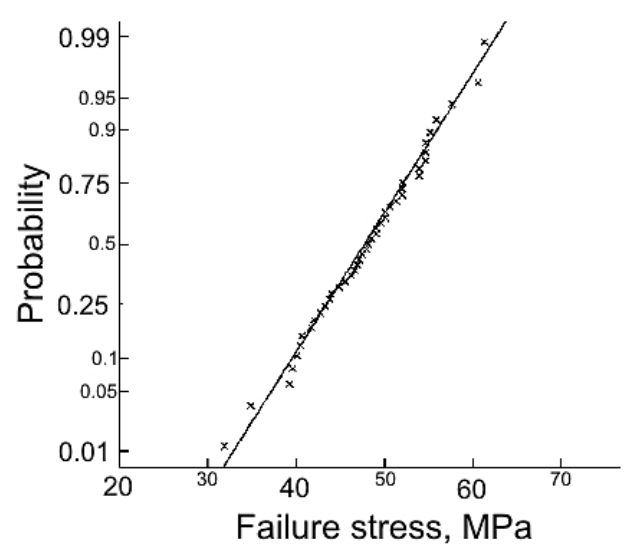

a

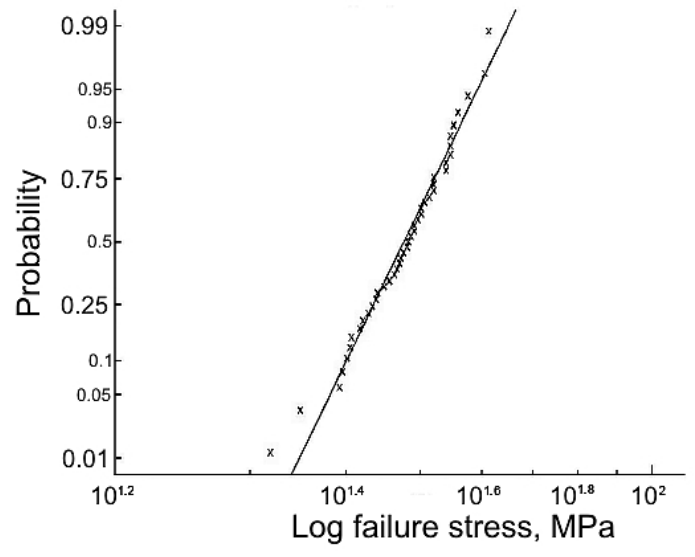

b

Fig. 10. Normal (a) and lognormal (b) distribution plot for cut left data set (standing).

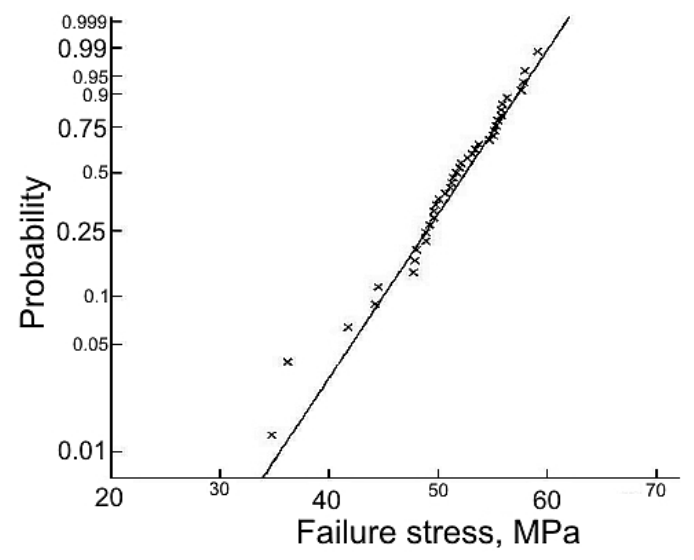

a

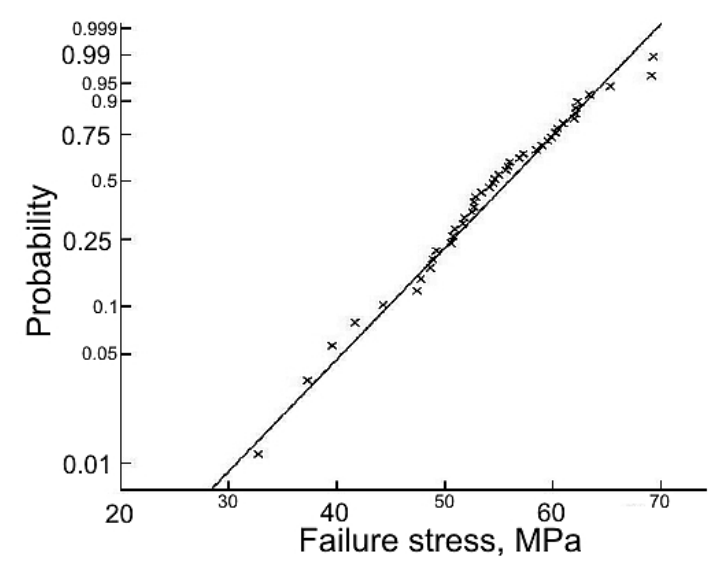

b

Fig. 11. Extreme value distribution probability plot for cut down - flat tests (a) and cut right data set - standing tests (b).

(iii) extreme value;

(iv) exponential;

(v) Rayleigh;

(vi) Weibull.

These are analyzed using normal probability plots for the best fit of the distribution. If the points fall on the straight line the distribution fits. In general, the problem lies at the maximum and minimum values. Only in some cases a reasonable fit occurs. This is given in Table 5 and Figs. 10-12. In practice. there is no single statistical descriptor that gives a universal fit on all valid test results. 


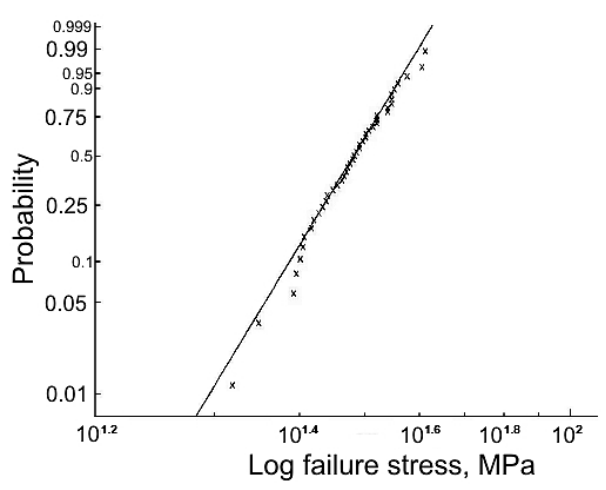

a

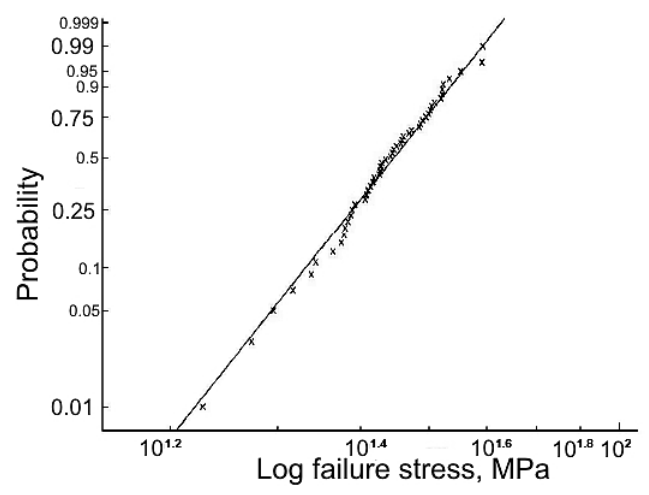

b

Fig. 12. Weibull distribution probability plot for cut left (a) and cut right (b) data set (standing tests).

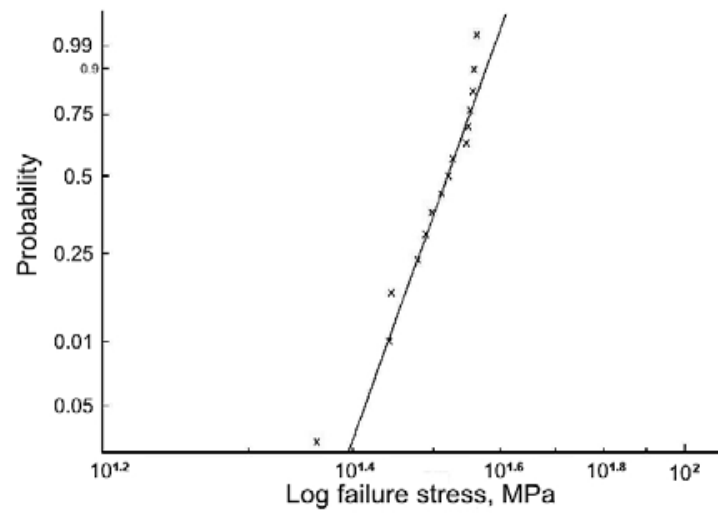

a

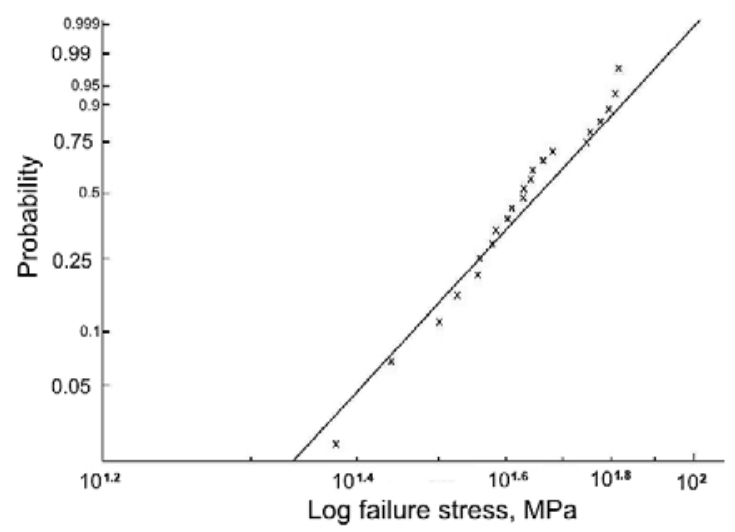

c

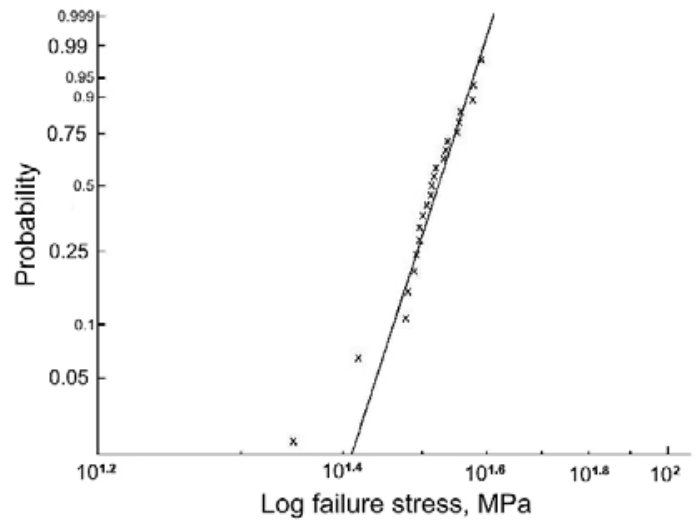

b

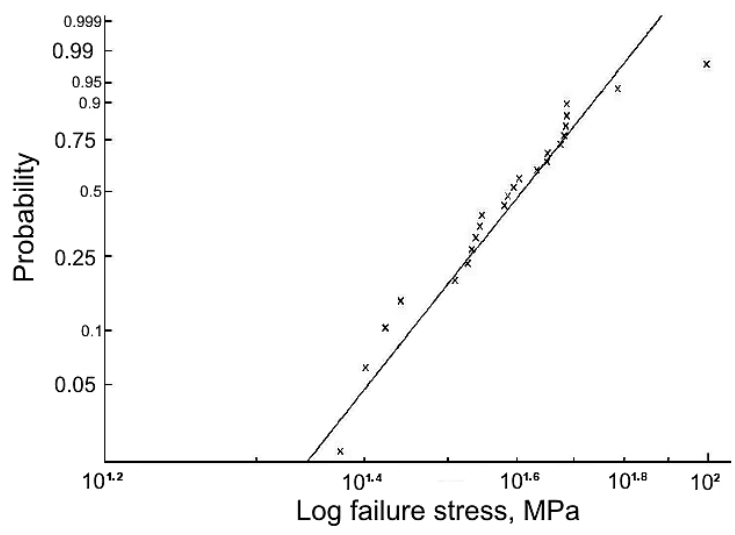

d

Fig. 13. Weibull plot of data subdivided into: fracture from left (a) or right (b) for the cut down data sets and from left (c) or right (d) for the cut up data sets (flat tests).

Analysis of Partial Data Sets. By splitting the cut up and cut down data sets for flat tests into subsets with fracture from the left or from the right we obtain the Weibull plot shown in Fig. 13. The partial data sets seem to fit the Weibull function better than the mixed data sets. The extremes at top and bottom are again the problem.

Figure 14 shows the cut left data (standing tests), separated to failure from the cut and failure not from the cut. The partial data set for failure not from the cut fits the Weibull function much better (Fig. 14a and curve 1 in Fig. 14b). For the failure from the cut (curves 2 and 3 in Fig. 14b) the bimodal Weibull function is better on account of three lowest strength values deviate (curve 3 in Fig. 14b). 


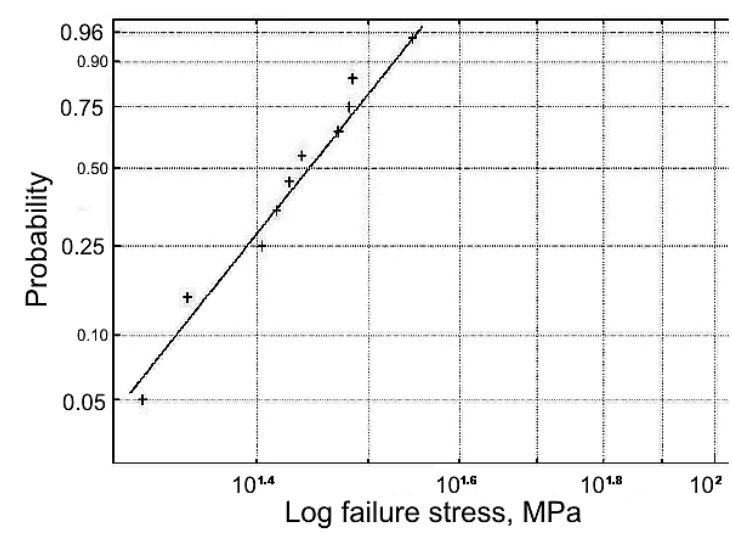

a

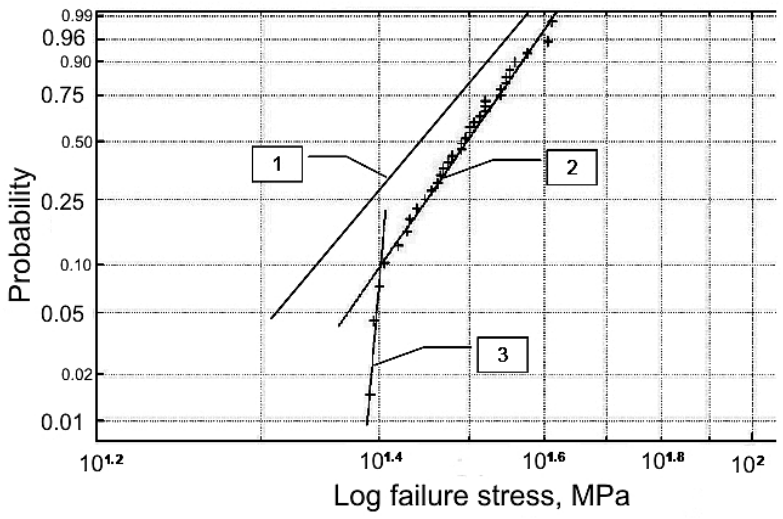

b

Fig. 14. Weibull plot of cut left data (standing tests) subdivided into: fracture not from cut (a) and (b, curve 1), and fracture from cut (b, curves 2 and 3 ).

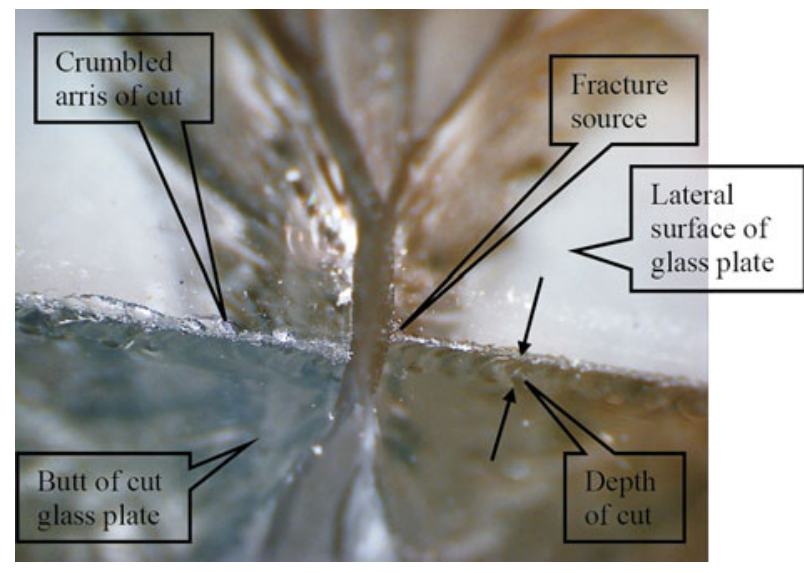

Fig. 15

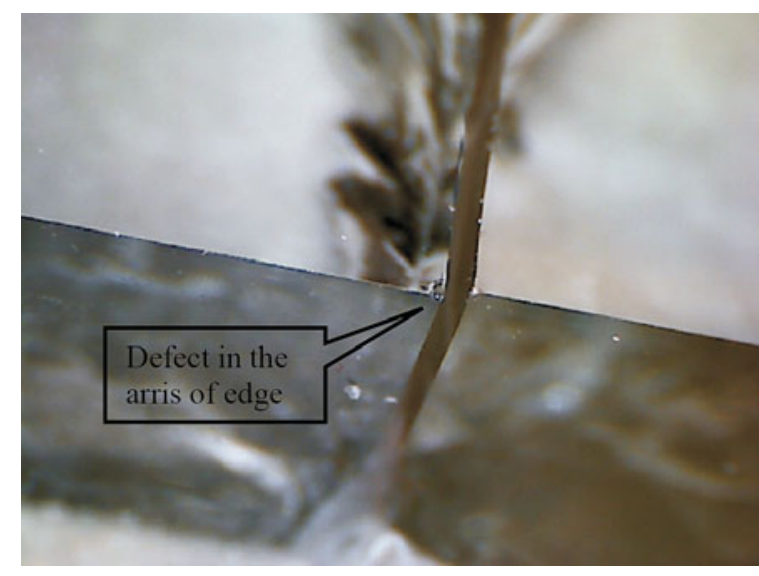

Fig. 16

Fig. 15. Failure point of cut right standing specimen No. 50 (Table 5), $\times 30$.

Fig. 16. Failure from the damaged arris in the uncut side in cut left specimen No. 30 (Table 5).

Fractography. A microscope was used to look at the failure origins. For the standing cut right series all failures started at the cut. This is shown in Fig. 15. The depth of cut as well as crumbled arris of cut are clearly visible in the butt of the cut glass specimen.

Fractographic analysis of the cut left data shows that of 44 valid results 34 specimens failed from the cut and 10 from the other side. Figure 16 shows a failure from the damaged arris on the uncut side of specimen.

Relation between Number of Cracks and Failure Stress. Figure 17 shows a plot between the number of cracks branching from the failure point and the failure stress. There is an approximately linear relation with very large deviations. However, the slopes of flat and standing tests differ by a factor of three.

Strength of Cut Specimens with a High-Quality Broken Arris of the Edge. The results from the flat tests of additional specimens with a high-quality cut glass edge working and safely handled are given in Table 6 . The undamaged broken edge arris of these specimens was in the tension zone.

Discussion. A significant amount of results have been presented. There are several possible conclusions that can be drawn from this. The most important is that the cutting process produces unequal sides. There is a significant effect if the cut is the source of failure. The average strength is some $20 \%$ less compared with the tests where the cut is on the compression side. The data is however much more homogeneous. The relative standard deviation is half compared to the tests where the cut is on the compression side. Even if both sides would follow a perfect Weibull 
TABLE 6. Results of the Flat Tests for Specimens with High-Quality Broken Arris

\begin{tabular}{|c|c|c|c|c|c|c|c|}
\hline No. & $\begin{array}{c}\sigma_{b \max }, \\
\mathrm{MPa}\end{array}$ & $\begin{array}{c}\text { Test speed, } \\
\mathrm{mm} / \mathrm{min}\end{array}$ & $\begin{array}{c}\text { Loading } \\
\text { speed, } \\
\mathrm{MPa} / \mathrm{s}\end{array}$ & $\begin{array}{c}\text { Mean value } \\
\text { of } \sigma_{b \max }, \\
\mathrm{MPa}\end{array}$ & $\begin{array}{c}\text { std } / \text { mean, } \\
\%\end{array}$ & $\begin{array}{c}\text { Maximum } \\
\text { value of } \\
\sigma_{b \max }, \mathrm{MPa}\end{array}$ & $\begin{array}{c}\text { Minimum } \\
\text { value of } \\
\sigma_{b \max }, \mathrm{MPa}\end{array}$ \\
\hline 1 & 148 & 4.900 & 1.560 & \multirow[t]{6}{*}{146} & \multirow[t]{6}{*}{15} & \multirow[t]{6}{*}{160} & \multirow[t]{6}{*}{114} \\
\hline 2 & 151 & 4.920 & 1.600 & & & & \\
\hline 3 & 114 & 4.660 & 1.520 & & & & \\
\hline 4 & 157 & 4.930 & 1.600 & & & & \\
\hline 5 & 160 & 4.770 & 1.600 & & & & \\
\hline 6 & 145 & 4.950 & 1.610 & & & & \\
\hline 7 & 137 & 0.494 & 0.161 & \multirow[t]{5}{*}{149} & \multirow[t]{5}{*}{11} & \multirow[t]{5}{*}{170} & \multirow[t]{5}{*}{131} \\
\hline 8 & 131 & 0.488 & 0.158 & & & & \\
\hline 9 & 162 & 0.526 & 0.170 & & & & \\
\hline 10 & 147 & 0.492 & 0.160 & & & & \\
\hline 11 & 170 & 0.497 & 0.161 & & & & \\
\hline
\end{tabular}

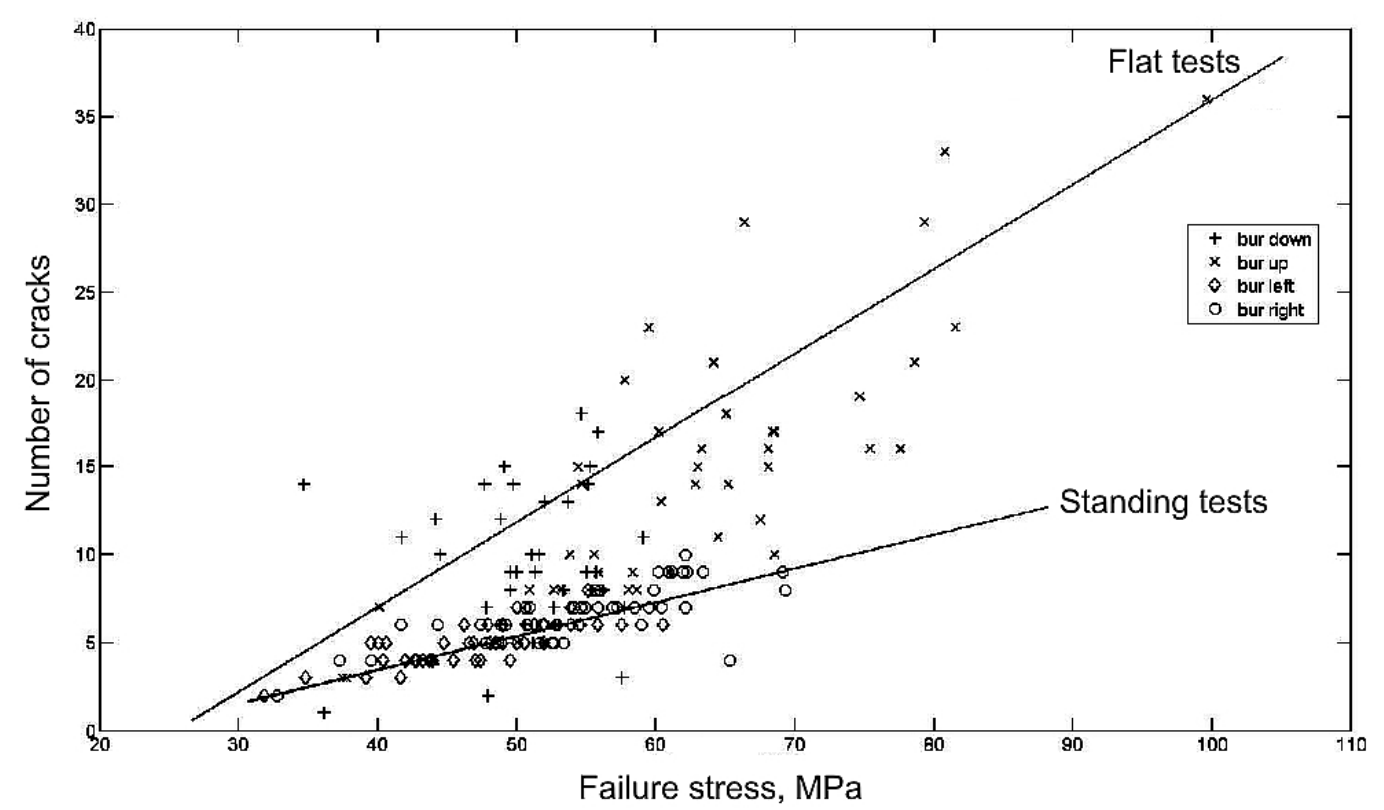

Fig. 17. Relation between the number of cracks and the failure stress.

distribution, the mixed data would not give a good Weibull distribution. As the Weibull distribution of both sets is considerably less than perfect, any resultant combination of course should totally deviate.

The statistical analyses initially suggest that there is no single distribution that fits all data. Of course this would only be valid if the data sets are really the result of a single causative operation and are independent. At best the statistical results can indicate that there is no single valid parameter or that the Weibull parameter is better or worse than any other parameter.

More interesting is the good fit for the standing tests with the cut on the right. There can be a deterministic explanation for this. Glass is an unyielding material and it is very unlikely that the test setup places the specimen perfectly straight. More likely is a small misalignment such as shown, exaggerated, in Fig. 18. This would explain the relatively high number of failures from the upper loading which go outside of the area between the loading span as the load would be transferred mostly onto an edge. In the tensile zone, the cut would be the most highly stressed part, especially the corner edge. Apparently the misalignment forces the specimens to fail from a single geometrical position and thus results in a single Weibull distribution. 


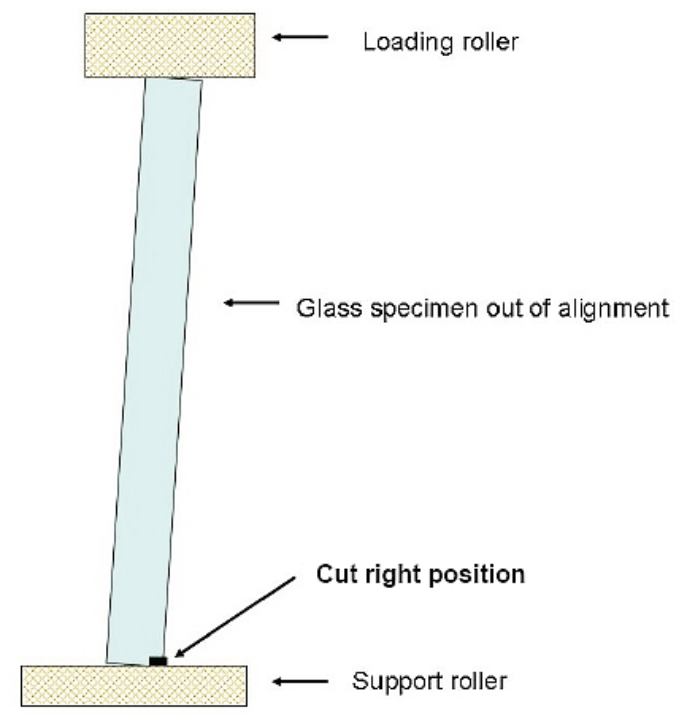

Fig. 18. Proposed alignment problem for the cut right standing tests.

If we compare the Weibull plots of the partial flat specimen data sets, separated to failure from the left and from the right in Fig. 13 an improved Weibull fit is visible, especially for the bur-down tests (Fig. 13a and b). The higher homogeneity of damages under glass cutting is the cause of that.

Presumably by separating the data further to source of fracture we might be able to obtain a series of single Weibull lines. The inherent multilinear Weibull behavior of cut float glass is thus the result of combining incomparable data sets.

If the cut glass is grinded and polished, the edges should become more equal. The reality of any process is of course that it has statistical results. The authors have regularly seen glass that has been grinded and polished, even tempered, on which parts of the cut or original crumbled arris of cut are still visible. In one case glass went into a tempering furnace with the cut surface still visible on about $50 \%$ of the edge surface.

Even if just enough of the glass was grinded to remove the bur and the protruding edge areas, the excess forces applied during the grinding could easily cause further surface microcrack growth and microdamage at areas of very poor surface quality. In any case, it would be impossible to see the original orientationon the grinded surface. As the data sets for grinded and polished large-size glass specimens are similar to those of cut glass, it is reasonable to assume that invisible damage from the cutting process influences the failure process of grinded and polished glass as shown in Fig. 19.

The standing test results allow us to evaluate the most probable lower value of glass plate strength as they include damages on all edge surfaces - on the Tin, nitrogen sides and bur as well as damages on both arrises. The Weibull plots of diamond cut specimens standing test results based on the data of Table 5 together with previous experimental data on size effect influence on grinded and polished glass strength (Table 2, Fig. 10 [8]) are given in Fig. 19.

Curves 1-4 show the test results for $8 \mathrm{~mm}$ float glass grinded and polished specimens series A, B, C and D with a load span $l=0.9,0.45,0.225$, and $0.1125 \mathrm{~m}$ [8]. For comparison with these data the curves 5 and 6 for diamond cut $6 \mathrm{~mm}$ specimens with cut left and cut right are given. It is obvious that angle of slope of lower part of multilinear curves 4,5, and 6 is closer to angle of slope of single Weibull line 1 for large-size specimens. But the minimal strength value for small grinded and polished specimens (curve 4) is significantly larger than the minimal value of large specimens (curve 1 ) as a result of large difference of their edge "hidden damages." Quite the contrary, curves 5 and 6 are close to curve 1 for probability of fracture less than 0.05 . Thus, low-quality processing and rough handling are the reasons for "hidden damage" effect on engineering strength of float glass.

This approach is corroborated by the new test results on the strength of specimens with a high-quality edge given in Table 6 . The minimal strength values for both series of specimens of $6 \mathrm{~mm}$ float glass tested at various 


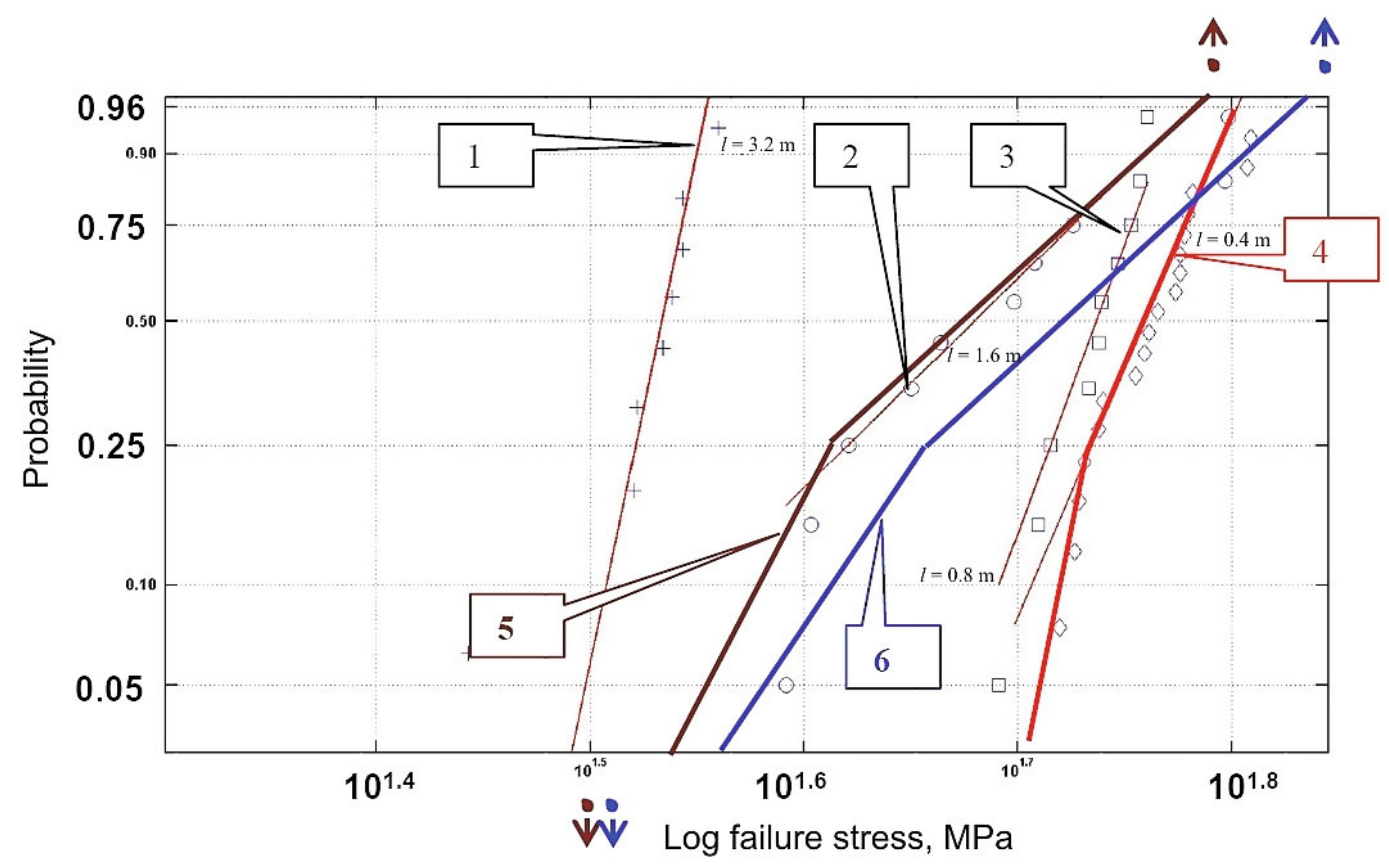

Fig. 19. Weibull plot of standing test results with cut edge left and right in reference to roller cut, grinded, and polished specimens with different load span: (1) $l=0.9 \mathrm{~m}$; (2) $l=0.45 \mathrm{~m}$; (3) $l=0.225 \mathrm{~m}$; (4) $l=0.1125 \mathrm{~m}$, roller cut, grinded, and polished [1]; (5) $l=0.175 \mathrm{~m}$, diamond cut, cut edge left; (6) $l=0.175 \mathrm{~m}$, diamond cut, cut edge right.

loading speeds are within the range of $115-130 \mathrm{MPa}$, which is more than twice higher than that of the grinded and polished specimen series $\mathrm{C}$ and $\mathrm{D}$ in flat tests (60 and $50 \mathrm{MPa}$ ) [8]. Standard deviation for these specimens' strength was comparable with series $\mathrm{S}$ and $\mathrm{D}$ - within the range of 10-15\% of average. Average values 145-150 MPa and the maximal values of strength 160-170 MPa reach the level of fully tempered glass strength. In contrast to tempered glass, fracture of these high-strength specimens was localized around the fracture source. Very small "central" surface defects - microcracks on side face are typical for tested high-quality float glass specimens. Just these initial microcracks in the thin cracked surface layer of high-quality sheet glass are the fracture source in the absence of large edge or side face "hidden damages" of glass elements.

These results show that "hidden damages" are the reason for the low structural strength of glass in usual practice. But these damages may be controlled and eliminated using the proposed approach and experimental data on glass structural strength together with advanced glass processing technology and industrial methods of structural glass strength control.

\section{CONCLUSIONS}

1. The side of the glass that is rolled or scratched to create the cut is on average by $20 \%$ weaker than the other side.

2. The failure stress of the side of the glass that was rolled to create the bur is much more consistent than the results obtained with specimen failure from the other side.

3. The failure stress of the side opposite to the bur can be much higher than strength of specimens with cut edge in tension as well as than strength of ordinary mechanically treated specimens, reaching values of heatstrengthened and even fully tempered glass.

4. If failure is forced from a single part of the cut area, a single mode Weibull distribution is obtained.

5. If the data are sorted out according to failure from left or right and from cut side or uncut side, the Weibull distributions of the partial data sets are better than those of the combined data sets. 
6. The multilinear Weibull pattern of the mixed data of the cut glass is similar to that of grinded and polished glass.

7. It is suggested that invisible damage from the cutting process remains after grinding and polishing and is the underflat cause of the multilinear Weibull behavior.

Acknowledgments. The work of the students who did the experiments for this work as part of their MSc1 materials science course is acknowledged.

\section{REFERENCES}

1. J. G. R. Kingston and R. J. Hand, "Compositional effects on the fracture behaviour of alkali-silicate glasses," Fatigue Fract. Eng. Mater. Struct., 23, No. 8, 685-690 (2000).

2. M. K. Keshavan, G. A. Sargent, and H. Conrad, "Statistical analysis of the Hertzian fracture of pyrex glass using the Weibull distribution function," Mater. Sci., 15, No. 4, 839-844 (1980).

3. F. A. Veer, F. P. Bos, J. Zuidema, and T. Romein, "Strength and fracture behaviour of annealed and tempered float glass," in: A. Carpinteri (Ed.), Proc. of 11th Int. Conf. on Fracture (Turin, Italy) (2005), pp. 1-6 (CD-ROM).

4. F. A. Veer, F. P. Bos, and P. C. Louter, "The strength of annealed, heat strengthened and fully tempered float glass," Fatigue Fract. Eng. Mater. Struct., 32, No. 1, 18-25 (2009).

5. F. A. Veer, C. Louter, F. Bos, et al., "The strength of architectural glass," in: Proc. of Challenging Glass Conf. (Delft) (2008), pp. 419-428.

6. $\quad$ F. A. Veer, "The strength of glass, a nontransparent value," Heron, 52, No. 1, 87-104 (2007).

7. Y. M. Rodichev, "Problems of technological and constructional strengthening of glass for architecture and new fields of glass industry," in: Proc. of Glass Processing Days Conf. (Tampere) (1999), pp. 162-165.

8. F. A. Veer and A. C. Riemslag, "The strength of glass, size effects," in: Proc. of Glass Performance Days Conf. (2009), pp. 851-853. 